\title{
Statins and glycaemic control in individuals with diabetes: a systematic review and meta-analysis
}

\author{
Sebhat Erqou • C. Christine Lee • Amanda I. Adler
}

Received: 3 June 2014 / Accepted: 22 August 2014 / Published online: 23 September 2014

(C) Springer-Verlag Berlin Heidelberg 2014

\begin{abstract}
Aims/hypotheses Current evidence indicates that statins increase the risk of incident diabetes; however, the relationship between statins and glycaemic control in people with established diabetes has not been well characterised. To address this question, we conducted a meta-analysis of randomised controlled trials (RCTs) of statins in patients with diabetes for whom there was available data on glycaemic control.

Methods We identified studies published between January 1970 and November 2013 by searching electronic databases and reference lists. We included RCTs in which the intervention group received statins and the control group received placebo or standard treatment, with $>200$ participants enrolled, with the intervention lasting $>12$ weeks and with preand post-intervention $\mathrm{HbA}_{1 \mathrm{c}}$ reported. We combined studyspecific estimates using random-effects model meta-analysis. Results In a pooled analysis of nine trials involving 9,696 participants (4,980 statin, 4,716 control) and an average follow-up of 3.6 years, the mean $\mathrm{HbA}_{1 \mathrm{c}}$ of participants
\end{abstract}

Sebhat Erqou and C. Christine Lee are joint first authors.

Electronic supplementary material The online version of this article (doi:10.1007/s00125-014-3374-x) contains peer-reviewed but unedited supplementary material, which is available to authorised users.

S. Erqou $(\bowtie)$

Department of Medicine, Weill Cornell Medical College, 565 E 68th

St, Box 130, New York, NY 10065, USA

e-mail: see9003@med.cornell.edu

C. C. Lee

Department of Nutritional Sciences, University of Toronto, Toronto, ON, Canada

A. I. Adler

Institute of Metabolic Sciences, Addenbrooke's Hospital,

Cambridge, UK randomised to statins was higher than those randomised to the control group: mean difference $(95 \% \mathrm{CI})$ was $0.12 \%(0.04$, $0.20)$ or $1.3 \mathrm{mmol} / \mathrm{mol}(0.4,2.2) ; p=0.003$. There was moderate heterogeneity across the studies $\left(I^{2}=54 \%, p=0.014\right)$ not explained by available study-level characteristics. This review was limited by the small number of studies, available data on only three statins and sparse reporting on changes in use of glucose-lowering medications.

Conclusions/interpretation Statin treatment is associated with a modest increase in $\mathrm{HbA}_{1 \mathrm{c}}$ in patients with diabetes.

Keywords Diabetes mellitus - Glycaemic control · $\mathrm{HbA}_{1 \mathrm{c}} \cdot$ Meta-analysis $\cdot$ Statins $\cdot$ Systematic review
Abbreviations
CARDS Collaborative Atorvastatin Diabetes Study
DALI Diabetes Atorvastatin Lipid Intervention
RCT Randomised controlled trial

\section{Introduction}

Statin therapy is the cornerstone of primary and secondary prevention of cardiovascular disease [1]. As diabetes is an important risk factor for cardiovascular disease and is considered a cardiovascular disease risk equivalent, treatment guidelines indicate that most patients with diabetes would benefit from statin therapy [2-4]. Recent clinical guidelines from the American College of Cardiology and the American Heart Association recommended that all patients with diabetes who are 40-75 years of age should be placed on moderateor high-intensity statin therapy to prevent or delay cardiovascular disease [5].

Despite their important role in the prevention and delay of cardiovascular disease, there is evidence suggesting that 
statins worsen glycaemia and increase the risk of developing type 2 diabetes by approximately $10-12 \%[6,7]$. The effect of statins on incident diabetes appears to differ by dose and type, with higher doses conferring higher risk than lower doses [8] and with atorvastatin and rosuvastatin being associated with a higher risk than pravastatin [9]. However, the effect of statins on glycaemic control in patients with pre-existing diabetes is less clear. Some studies have reported that statins may adversely affect the glycaemic profile, with a mean increase in $\mathrm{HbA}_{1 \mathrm{c}}$ concentration of $0.3 \%$ or less in patients with diabetes [7, 10-13], while other studies have reported no worsening or even a potential benefit of statins on the glycaemic control in patients with diabetes [14-16]. However, most studies were either observational studies or uncontrolled trials, were small in size and had short follow-up periods limiting the available evidence to delineate the effect of statins on glycaemic control in diabetes $[10,17]$. This is further complicated by the potentially important differences between different statin types and doses; for instance, a number of studies have suggested that treatment with atorvastatin, but not pitavastatin, may lead to significant deterioration in glycaemic control in patients with diabetes $[11,17,18]$. In this study, we conducted a metaanalysis of randomised controlled trials (RCTs) to assess the effects of statin therapy on glycaemia, as measured by $\mathrm{HbA}_{1 \mathrm{c}}$, in patients with diabetes.

\section{Methods}

Literature search We sought RCTs of statins comprised either entirely, or containing a subgroup, of patients with type 1 or type 2 diabetes with available data on $\mathrm{HbA}_{1 \mathrm{c}}$ concentrations before and after statin therapy. Two authors (S. Erqou, C. C. Lee) systematically and independently searched the electronic databases of MEDLINE and EMBASE for studies published between January 1970 and November 2013, using key terms related to diabetes, statins and glycaemia. We searched MEDLINE using medical subject heading (MeSH) terms and free text keywords related to 'haemoglobin $\mathrm{A}_{1 \mathrm{c}}$ ', 'diabetes mellitus' and 'statins'. We also searched EMBASE using 'map term to subject heading' in Advanced Ovid Search, using similar search terms. We supplemented the literature search by scanning the reference lists of relevant articles.

Study selection The database search identified 718 citations from MEDLINE and 434 citations from EMBASE. Two authors (S. Erqou, C. C. Lee) accessed the titles, abstracts and/or full texts, and selected potentially relevant studies based on pre-defined inclusion criteria. We included RCTs in which the intervention group received statins and the control group received placebo or standard treatment, with $>200$ participants enrolled, with intervention lasting $>12$ weeks and with pre- and post-intervention $\mathrm{HbA}_{1 \mathrm{c}}$ reported. Glycaemic control need not have been the primary endpoint of the trials. Where a study had duplicate publications $[19,20]$, we selected the report with the largest number of participants [20]. Nine studies [16, 20-27] met the inclusion criteria and were included in the current report (Fig. 1).

Data extraction Two authors (S. Erqou, C. C. Lee) used standardised forms to extract information from the publications. We extracted data on the type of diabetes, time since diagnosis, type and dose of statins in interventions, duration of follow-up, baseline and follow-up $\mathrm{HbA}_{1 \mathrm{c}}$ concentrations (with their SDs) and, where available, the proportion of participants receiving glucose-lowering medications or insulin at baseline and at follow-up. To help better understand the included studies, we also extracted information on baseline characteristics of the participants, including demographics (e.g. age, sex, ethnicity), medical history (e.g. history of hypertension and cardiovascular disease), clinical variables (e.g. blood pressure, BMI) and laboratory data (e.g. serum LDL-cholesterol, triacylglycerols). We also sought data on differences in use of oral hypoglycaemic agents between patients randomised to statin and control, but the data were too limited for analyses.

Data analysis Of the nine clinical trials included in the present analysis, three $[20,21,27]$ reported their results in two subgroups (Table 1); we analysed these separately, giving a total of 12 data points in the meta-analysis. To limit potential

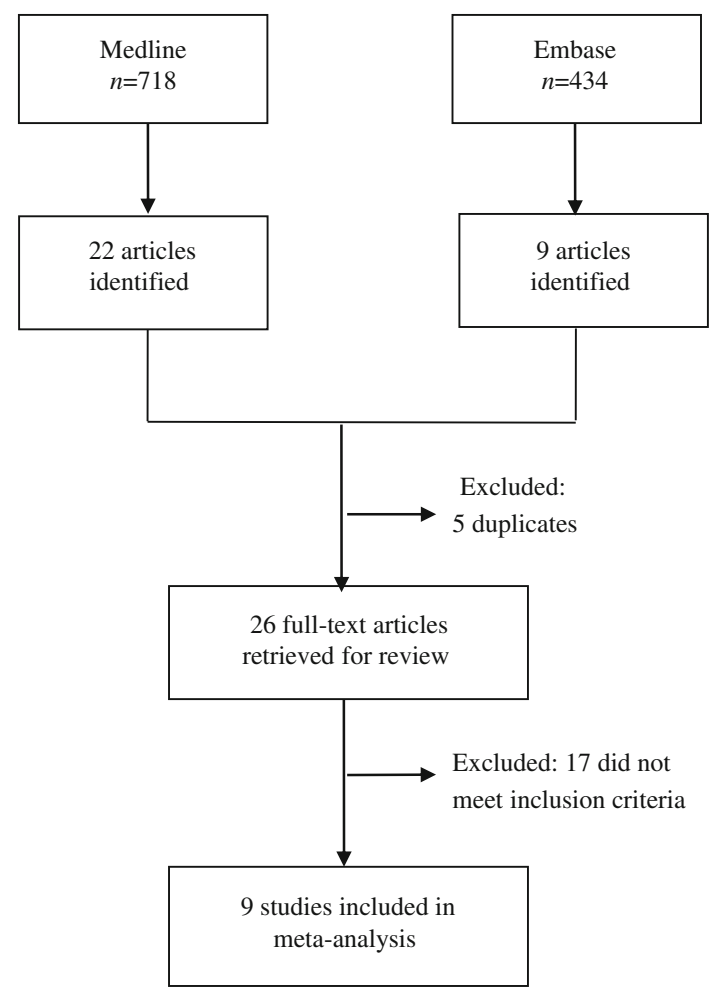

Fig. 1 Study flow diagram 


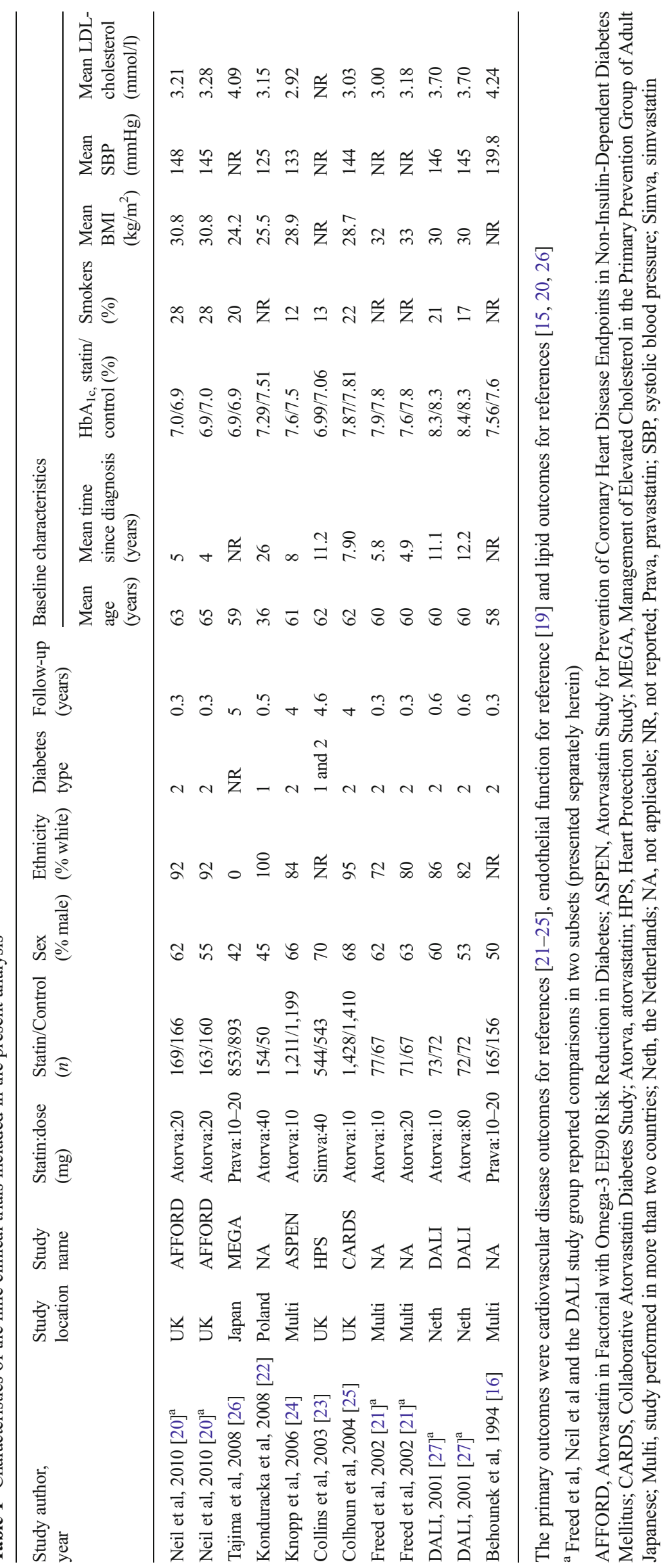


bias arising from between-study differences with regards to statin therapy, mean $\mathrm{HbA}_{1 \mathrm{c}}$ concentrations and measurement methods, we performed all analyses using only within-study comparisons. The quality of the studies was assessed using US Preventive Task Force quality rating criteria for RCTs, the Jadad score [28]. We calculated the mean $\mathrm{HbA}_{1 \mathrm{c}}$ concentration difference at follow-up between patients randomised to statin and those randomised to control. We estimated the variance of the mean $\mathrm{HbA}_{1 \mathrm{c}}$ difference between the statin and control groups by summing the individual variances of mean $\mathrm{HbA}_{1 \mathrm{c}}$ concentration for the statin and treatment groups. The variance of the mean $\mathrm{HbA}_{1 \mathrm{c}}$ concentration was estimated by dividing the variance of the $\mathrm{HbA}_{1 \mathrm{c}}$ concentration by the number of participants in the group; the square root of the variance gave the standard error of the mean $\mathrm{HbA}_{1 \mathrm{c}}$. We pooled the mean $\mathrm{HbA}_{1 \mathrm{c}}$ difference across the studies (and subgroups) using random-effects model meta-analysis, which makes allowance for between-study heterogeneity [29]. We also pooled the mean $\mathrm{HbA}_{1 \mathrm{c}}$ concentration at follow-up in the statin and control groups separately using similar methods. We reported the main effect of statins (i.e. mean difference in $\mathrm{HbA}_{1 \mathrm{c}}$ concentration) in both traditional units (as percentages) and International Federation of Clinical Chemistry and Laboratory Medicine (IFCC) units (as mmol/mol) [30]. We provided pooled estimates along with their $95 \%$ CIs. For comparison, we combined the estimates using fixed-effect model meta-analysis.

We assessed heterogeneity between studies using $Q$ and $I^{2}$ statistics. The $Q$ statistic is the $\chi^{2}$ test for heterogeneity with a degree of freedom equal to one minus the number of studies included in meta-analysis; this assesses whether observed differences in results between studies are due to chance alone [31]. The $I^{2}$ statistic estimates the percentage of total variation across studies due to a true difference rather than chance [32]. In general, $I^{2}$ values greater than $60-70 \%$ indicate the presence of substantial heterogeneity. We explored sources of heterogeneity by comparing the mean differences in $\mathrm{HbA}_{1 \mathrm{c}}$ between subgroups defined by the following study-level characteristics: mean baseline $\mathrm{HbA}_{1 \mathrm{c}}$, type of statin used, diabetes type, diabetes duration and follow-up duration. We assessed the presence of publication bias by using funnel plot and the Egger test of bias [33]. Statistical tests were two-sided and used a significance level of $p<0.05$. We performed all analyses using Stata 13 (Stata Corp LP, College Station, TX, USA).

\section{Results}

Nine clinical trials [16, 20-27] involving 9,696 participants (4,980 statin, 4,716 control) were included in the current analysis. While all the included studies reported glycaemic control as an outcome, their primary endpoints were incident cardiovascular diseases or other outcomes such as LDLcholesterol concentration or endothelial function. The participants randomised to statin and control groups within each study were generally similar with regards to several baseline characteristics, indicating successful randomisation. Details of the studies analysed are shown in Table 1 . The proportion of men in the studies ranged between $42 \%$ and $70 \%$ (weighted average, $61 \%$ ). The average age of the participants by study ranged between 36 and 65 years (weighted average, 60 years). Six studies included only patients with type 2 diabetes, one study included patients with type 1 diabetes and another study included both patients with type 1 diabetes and with type 2 diabetes. The average time since diagnosis of diabetes ranged between 4 and 26 years. The participants had been followed for an average of 4 months to 5 years (weighted average, 3.6 years). In studies that reported their assay methods, HPLC was used to measure $\mathrm{HbA}_{1 \mathrm{c}}$. The Jadad quality assessment of the trials showed that most scored 4 and 5 points (out of 5), while two studies $[22,26]$ scored 3 points (electronic supplementary materials [ESM] Tables 1,2). The mean baseline $\mathrm{HbA}_{1 \mathrm{c}}$ across the studies (weighted average) was $7.46 \%$ $(58 \mathrm{mmol} / \mathrm{mol})$ in the statin group and $7.43 \%(57.7 \mathrm{mmol} /$ mol) in the control group.

Three of the studies reported their results in two subsets. Freed et al [21] compared the effect of atorvastatin at doses of $10 \mathrm{mg}$ and of $20 \mathrm{mg}$. Neil et al [20] compared the effect of atorvastatin at a dose of $20 \mathrm{mg}$ in four arms, where one statin and one control group received an additional omega-3 supplement. The Diabetes Atorvastatin Lipid Intervention (DALI) study group [27] compared the effect of atorvastatin at doses of $10 \mathrm{mg}$ and $80 \mathrm{mg}$. We analysed these subsets separately, giving a total of 12 comparisons. Subsidiary analyses by combining the subsets using fixed-effect model metaanalysis before pooling with the rest of the studies yielded very similar results.

In random-effects model analysis, the pooled $\mathrm{HbA}_{1 \mathrm{c}}$ concentration at follow-up was $7.53 \%(95 \%$ CI $7.20,7.86)$ in the statin group and $7.41 \%(95 \% \mathrm{CI} 7.11,7.72)$ in the control group (Fig. 2). The pooled mean $\mathrm{HbA}_{1 \mathrm{c}}$ difference across the studies involving participants with type 2 diabetes only was $0.17 \%$ (95\% CI $0.07,0.27)$, while the pooled estimate for the three studies involving participants with type 1 diabetes, a mixed population or unknown diabetes type was $0.03 \%$ (95\% CI $-0.08,0.14$ ) (Fig. 3). The overall pooled mean difference in $\mathrm{HbA}_{1 \mathrm{c}}$ was $0.12 \%$ (95\% CI 0.04, 0.20, $\left.p=0.003\right)$ (Fig. 3 and ESM Fig. 1) and the corresponding value in fixed-effect model analysis was $0.13 \%$ (95\% CI $0.08,0.17, p<0.001)$. (ESM Fig. 2) The corresponding value of the overall pooled estimate in SI units was $1.3 \mathrm{mmol} / \mathrm{mol}(95 \%$ CI $0.4,2.2)$. There was moderate heterogeneity across the studies $\left(I^{2}=\right.$ $54 \%, p=0.014)$, not explained by available study-level characteristics; however, we observed a trend towards a stronger effect for trials on atorvastatin compared with trials on 
Fig. 2 Average follow-up $\mathrm{HbA}_{1 \mathrm{c}}$ levels in nine clinical trials of statins in diabetes. ${ }^{\text {a }}$ Studies by Neil et al, Freed et al and the DALI study group reported comparisons in two subgroups and are presented here separately. Black boxes represent the $\mathrm{HbA}_{1 \mathrm{c}}$ concentration in $\%$ and the horizontal bars show the $95 \%$ CIs. proportional to the inverse the pooled effect estimate and 95\% CI and the dotted vertical line centred on the diamond has been added to assist visual interpretation. Atorva, atorvastatin; Prava, pravastatin; values for $\mathrm{HbA}_{1 \mathrm{c}}$ in \% into $\mathrm{mmol} / \mathrm{mol}$, subtract 2.15 and multiply by 10.929 The size of the boxes is variance. The diamond represents Simva, simvastatin. To convert

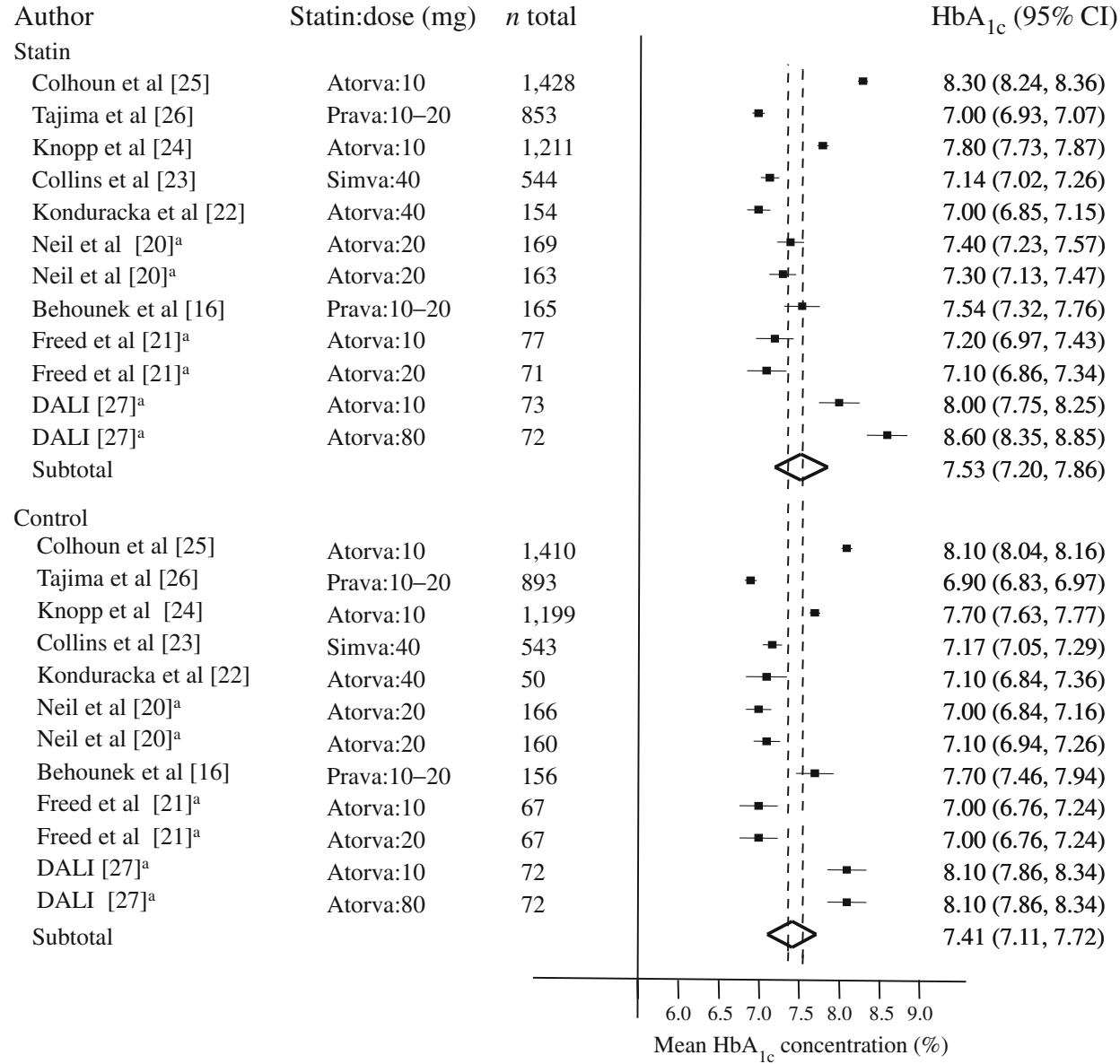

pravastatin or simvastatin, for trials that comprised participants with type 2 diabetes compared with those comprised of participants with type 1 diabetes or mixed populations and also for trials in which there was larger reduction in LDL-cholesterol $(>1.1 \mathrm{mmol} / \mathrm{l})$ compared with those with smaller reduction in LDL-cholesterol $(<1.1 \mathrm{mmol} / \mathrm{l})$ (Fig. 4). There was no strong evidence suggesting the presence of publication bias (i.e. there was no funnel-plot asymmetry and Egger's test for bias was not statistically significant $[p=0.80]$ ).

\section{Discussion}

Currently available trial data, involving predominantly participants with type 2 diabetes, indicate a modest effect of statin use on $\mathrm{HbA}_{1 \mathrm{c}}$ concentration. In a pooled analysis of nine trials involving 9,696 participants and an average follow-up of 3.6 years, we found that the mean $\mathrm{HbA}_{1 \mathrm{c}}$ of participants randomised to statins was $0.12 \%(95 \%$ CI $0.04,0.20)$ higher than those randomised to control. There may have been heterogeneity of effect among the three statins studied in these trials (atorvastatin, pravastatin and simvastatin), but more studies are needed to determine whether atorvastatin has a stronger effect given the limited data available on pravastatin and simvastatin in this meta-analysis. Similarly, further data are needed to determine the possible heterogeneity of effect by type of diabetes or by degree of LDL-cholesterol reduction noted in this meta-analysis.

The small effect of statins on $\mathrm{HbA}_{1 \mathrm{c}}$ concentration observed in this meta-analysis, although statistically significant, may have little clinical impact. For example, while a $1 \mathrm{mmol} / \mathrm{l}$ lowering of LDL-cholesterol (all other things being equal) might be expected to reduce the risk of cardiovascular disease by approximately $20 \%$ [34], a $0.12 \%$ increase in $\mathrm{HbA}_{1 \mathrm{c}}$ would not be expected to have material effect on cardiovascular disease risk [35]. However, various statin types and doses may have differing adverse effects on glycaemic control, as indicated in previous reports $[11,17,18]$, as well as being implied in our study where we found a trend towards this, which may have attenuated the pooled effect in the current meta-analysis. Furthermore, in clinical trials that spanned a longer period of follow-up, there may have been a differential change in glucose-lowering medications of participants randomised to statin and control arms that could potentially offset the effect of statin therapy. The current analysis, 


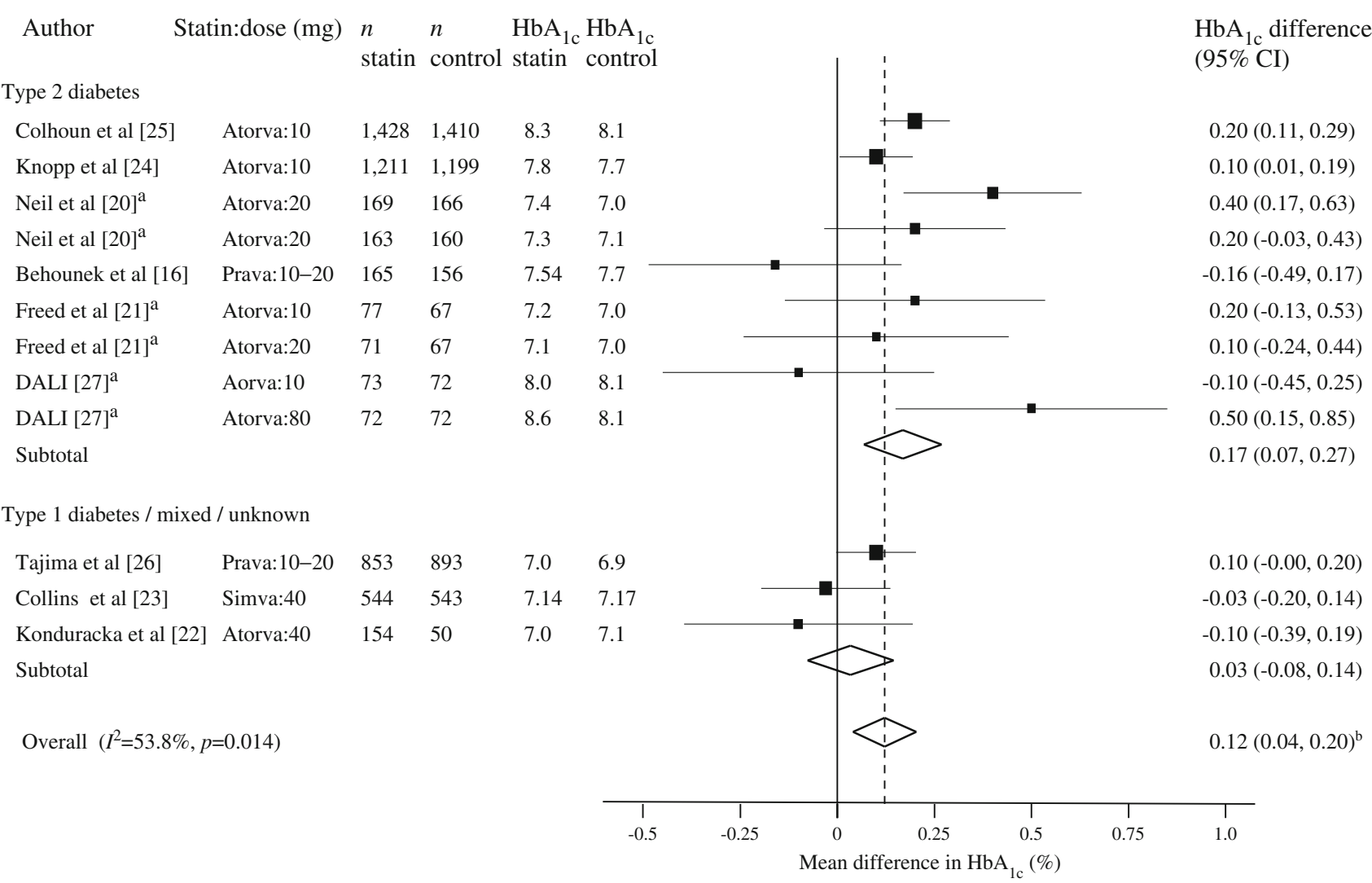

Fig. 3 Mean difference in $\mathrm{HbA}_{1 \mathrm{c}}$ at follow-up in nine clinical trials of

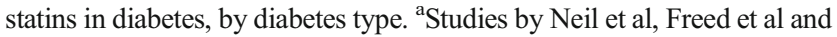
the DALI study group reported comparisons in two subgroups and are presented separately herein. ${ }^{b}$ The overall $p$ value for main effect of statin was 0.003 . For explanation of abbreviations and symbols, see the legend to Fig. 2. To convert values for $\mathrm{HbA}_{1 \mathrm{c}}$ in $\%$ into $\mathrm{mmol} / \mathrm{mol}$, subtract 2.15 and multiply by 10.929 therefore, raises awareness of clinicians to the potential dysglycaemic effect of statins in diabetic patients.

The magnitude of effect of statin use on glycaemic control among patients with diabetes that we observed in our study (i.e. a $0.12 \%[1.3 \mathrm{mmol} / \mathrm{mol}]$ absolute increase in mean $\mathrm{HbA}_{1 \mathrm{c}}$ concentration [equivalent to $0.02 \%$ higher $\mathrm{HbA}_{1 \mathrm{c}}$ level]), is smaller than the effect of statin use on the risk of new-onset diabetes reported in a previous meta-analysis of randomised clinical trials (approximately 10\% increase in risk) [6]. This difference may be at least partly artefactual given that the quality and amount of data available for the two metaanalyses are not comparable. However, such differences have been observed within large RCTs as well; for example, the Justification for the Use of Statins in Primary Prevention (JUPITER) study showed a materially greater increase in the risk of new-onset diabetes ( $26 \%$ higher risk) compared with a mean increase in $\mathrm{HbA}_{1 \mathrm{c}}$ of $0.3 \%$ for individuals randomised to rosuvastatin vs control $[7,36]$. Possible explanations for the observed weaker effect of statin use on $\mathrm{HbA}_{1 \mathrm{c}}$ concentration in diabetes include bias due to differential attrition or adjustment of hypoglycaemic medication between the statin and control groups [7]. For instance, in the Collaborative Atorvastatin Diabetes Study (CARDS), 20\% of the participants randomised to the statin arm vs $17 \%$ of those randomised to the control arm were switched to insulin or had insulin added to their treatment regimen by the end of the follow-up period [25].

A number of mechanisms have been proposed to explain the potential adverse effect of statins on glycaemic control. Statins may downregulate GLUT4, a membrane transport protein that plays a role in the uptake of glucose by adipocytes. Statins may also decrease insulin secretion. In addition, statins may be associated with increased insulin resistance [4, 17, 37-41]. The trend towards stronger association among patients with type 2 diabetes than among those with type 1 diabetes observed in the current analysis may corroborate the proposed mechanism of statin effect on insulin resistance. In addition, observation of differences in effect on glycaemic control among the various statins suggests that differences in potency and/or lipid solubility may be important [4]. However, limited evidence is available on these proposed mechanisms and more data are needed to clarify these hypotheses.

Our study has a number of strengths worth mentioning. First, we conducted a comprehensive review by searching complementary databases and the reference list of relevant articles. Second, pooling data from RCTs allows us to make 


\begin{tabular}{|c|c|c|c|c|c|c|c|}
\hline Subgroup & $n$ comp $^{\mathrm{a}}$ & $n$ statin & $n$ control & & & $\begin{array}{l}\mathrm{HbA}_{1 \mathrm{c}} \text { difference } \\
(95 \% \mathrm{CI})\end{array}$ & $p$ value ${ }^{\mathrm{b}}$ \\
\hline \multicolumn{8}{|l|}{ Statin } \\
\hline Pravastatin & 2 & 1,018 & 1,049 & & - & $0.02(-0.22,0.25)$ & \\
\hline Simvastatin & 1 & 544 & 5,439 & & & $-0.03(-0.20,0.14)$ & \\
\hline \multicolumn{8}{|l|}{ Follow-up } \\
\hline$<1$ year & 8 & 944 & 810 & & 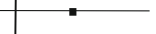 & $0.14(-0.03,0.30)$ & 0.68 \\
\hline$\geq 1$ year & 4 & 4,036 & 4,045 & & $\longrightarrow$ & $0.11(0.03,0.19)$ & \\
\hline \multicolumn{8}{|l|}{ Mean $\mathrm{HbA}_{1 \mathrm{c}}$} \\
\hline$<7.5 \%$ & 5 & 1,883 & 1,812 & & - & $0.11(-0.03,0.26)$ & 0.89 \\
\hline$\geq 7.5 \%$ & 7 & 3,097 & 3,043 & & & $0.13(0.02,0.24)$ & \\
\hline \multicolumn{8}{|c|}{ Time since diagnosis } \\
\hline$<5$ years & 2 & 234 & 227 & & & $0.17(-0.02,0.36)$ & 0.90 \\
\hline$\geq 5$ years & 8 & 3,728 & 3,579 & & 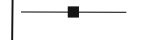 & $0.14(0.03,0.25)$ & \\
\hline \multicolumn{8}{|l|}{ Diabetes type } \\
\hline 1 or mixed & 2 & 698 & 593 & & - & $-0.05(-0.19,0.10)$ & 0.10 \\
\hline 2 only & 9 & 3,429 & 3,369 & & $\longrightarrow$ & $0.17(0.07,0.27)$ & \\
\hline \multicolumn{8}{|l|}{ LDL-c reduction } \\
\hline$<1.1 \mathrm{mmol} / \mathrm{l}$ & 6 & 4,355 & 4,251 & & & $0.08(-0.01,0.16)$ & 0.11 \\
\hline \multirow[t]{3}{*}{$\geq 1.1 \mathrm{mmol} / \mathrm{l}$} & 6 & 625 & 604 & & - & $0.23(0.07,0.39)$ & \\
\hline & & & $T$ & $T$ & 1 & $T$ & \\
\hline & & & -0.5 & -0.25 & 0.25 & 0.5 & \\
\hline
\end{tabular}

Fig. 4 Subgroup analysis of mean difference in $\mathrm{HbA}_{1 \mathrm{c}}$ in nine clinical trials of statins in diabetes. ${ }^{a} n$ comparisons may add up to $>9$, as Freed et al, Neil et al and the DALI study group reported two subsets (counted separately herein). ${ }^{\mathrm{b}}$ The $p$ values are tests of significance for difference

inferences about causality (i.e. that statins per se worsen glycaemia). Third, we used strict pre-defined criteria to ensure the quality of the trials included and to ensure their relevance to answering the clinical question. For instance, we excluded studies with $<3$ month follow-up period, as $\mathrm{HbA}_{1 \mathrm{c}}$ measures the average blood glucose concentration over a 3 month period. Finally, despite considerable differences between the studies, we did not observe either substantial heterogeneity in the meta-analysis or statistical evidence for publication bias.

There are also a few caveats that limit the inferences that can be made from the present analysis. First, there were a small number of studies with about 10,000 total participants available for this review. Second, while we conducted a comprehensive review of the published literature, we were not able to capture data from unpublished studies or informally published material, which might affect the pooled estimate. However, the effect of any bias due to such omission is likely to be minimal since the outcome of interest for this analysis (the effect of statins on glycaemic control) was different from the primary outcome of most of the individual studies (the effects of statins on lipid concentrations or cardiovascular disease risk). Third, we only had data on atorvastatin, pravastatin and one study on simvastatin, hence inferences regarding the between the subgroup effects. For explanation of abbreviations and symbols, see the legend to Fig. 2. To convert values for $\mathrm{HbA}_{1 \mathrm{c}}$ in $\%$ into $\mathrm{mmol} / \mathrm{mol}$, subtract 2.15 and multiply by 10.929

effect of different statins is limited. Fourth, the selected studies did not generally report changes in the use of glucoselowering medications, which might influence the effect of statins on $\mathrm{HbA}_{1 \mathrm{c}}$ concentration. Last, as the present work is a literature-based meta-analysis, we did not have access to individual participant data, and could not explore heterogeneity in detail. Although a number of RCTs of statins included people with diabetes, only the few studies we included reported $\mathrm{HbA}_{1 \mathrm{c}}$ concentration. In the future, a collaborative metaanalysis that pools together these data (both published and unpublished), allowing more detailed, consistent and powerful analyses, should help to provide a more definite answer than has been possible thus far.

The results of this study are not expected to change current clinical practice, insofar as the benefits of statins in patients with diabetes far outweigh the disadvantages, since statins reduce cardiovascular disease risk materially in this population [35] while their impact on glycaemic control is not certain. However, assuming a normal distribution of effect of statins on $\mathrm{HbA}_{1 \mathrm{c}}$ values, a significant proportion of patients might be expected to have statin-associated changes in $\mathrm{HbA}_{1 \mathrm{c}}$ of greater than 0.12 percentage points, possibly dependent on the type and dose of the statin. Hence, healthcare providers 
and patients may need to watch for worsening glycaemia in anticipation of intensifying statin treatment.

In conclusion, limited evidence indicates that statin treatment is associated with a modest increase in $\mathrm{HbA}_{1 \mathrm{c}}$ in patients with diabetes. Future collaborative meta-analysis of available randomised clinical trials would help to further characterise the effect of statins on glycaemic control in diabetes.

Acknowledgements We thank Professor Arthur Evans (Department of Medicine, Weill Cornell Medical College, New York, NY, USA) for insightful comments on the study design.

Duality of interest The authors declare that there is no duality of interest associated with this manuscript.

Contribution statement SE designed the study, wrote the manuscript, analysed and interpreted the data, revised the manuscript critically for important intellectual content and approved the final version for publication. CCL designed the study, interpreted the data, revised the manuscript critically for important intellectual content and approved the final version for publication. AIA interpreted the data, revised the manuscript critically for important intellectual content and approved the final version for publication. SE and CCL are responsible for the integrity of the work as a whole.

\section{References}

1. Sarwar N, Gao P, Seshasai SR et al (2010) Diabetes mellitus, fasting blood glucose concentration, and risk of vascular disease: a collaborative meta-analysis of 102 prospective studies. Lancet 375:2215-2222

2. Kearney PM, Blackwell L, Collins R et al (2008) Efficacy of cholesterol-lowering therapy in 18,686 people with diabetes in 14 randomised trials of statins: a meta-analysis. Lancet 37:117-125

3. Third Report of the National Cholesterol Education Program (NCEP) (2002) Expert panel on detection, evaluation, and treatment of high blood cholesterol in adults (adult treatment panel III) final report. Circulation 106:3143-3421

4. Rocco MB (2012) Statins and diabetes risk: fact, fiction, and clinical implications. Cleve Clin J Med 79:883-893

5. Stone NJ, Robinson J, Lichtenstein AH et al (2014) 2013 ACC/AHA guideline on the treatment of blood cholesterol to reduce atherosclerotic cardiovascular risk in adults: a report of the American College of Cardiology/American Heart Association Task Force on Practice Guidelines. Circulation 129(25 Suppl. 2):S1-S45

6. Sattar N, Preiss D, Murray HM et al (2010) Statins and risk of incident diabetes: a collaborative meta-analysis of randomised statin trials. Lancet 375:735-742

7. Maki KC, Ridker PM, Brown WV, Grundy SM, Sattar N (2014) An assessment by the statin diabetes safety task force: 2014 update. J Clin Lipidol 8(3 Suppl.):S17-S29

8. Preiss D, Seshasai SR, Welsh P et al (2011) Risk of incident diabetes with intensive-dose compared with moderate-dose statin therapy: a meta-analysis. JAMA 305:2556-2564

9. Carter AA, Gomes T, Camacho X, Juurlink DN, Shah BR, Mamdani MM (2013) Risk of incident diabetes among patients treated with statins: population based study. BMJ 346:f2610

10. Sasaki J, Iwashita M, Kono S (2006) Statins: beneficial or adverse for glucose metabolism. J Atheroscler Thromb 13:123-129
11. Takano T, Yamakawa T, Takahashi M, Kimura M, Okamura A (2006) Influences of statins on glucose tolerance in patients with type 2 diabetes mellitus. J Atheroscler Thromb 13:95-100

12. Kei A, Liberopoulos E, Elisaf M (2013) Effect of hypolipidemic treatment on glycemic profile in patients with mixed dyslipidemia. World J Diabetes 4:365-371

13. Simsek S, Schalkwijk CG, Wolffenbuttel BH (2012) Effects of rosuvastatin and atorvastatin on glycaemic control in type 2 diabetes - the CORALL study. Diabet Med 29:628-631

14. Liu PY, Lin LY, Lin HJ et al (2013) Pitavastatin and Atorvastatin double-blind randomized comPArative study among hiGh-risk patients, including thOse with Type 2 diabetes mellitus, in Taiwan (PAPAGO-T Study). PLOS ONE 8:e76298

15. Chapman MJ, Orsoni A, Robillard P, Hounslow N, Sponseller CA, Giral P (2014) Effect of high-dose pitavastatin on glucose homeostasis in patients at elevated risk of new-onset diabetes: insights from the CAPITAIN and PREVAIL-US studies. Curr Med Res Opin 30:775784

16. Behounek BD, McGovern ME, Kassler-Taub KB, Markowitz JS, Bergman M (1994) A multinational study of the effects of low-dose pravastatin in patients with non-insulin-dependent diabetes mellitus and hypercholesterolemia. Pravastatin Multinational Study Group for Diabetes. Clin Cardiol 17:558-562

17. Yamakawa T, Takano T, Tanaka S, Kadonosono K, Terauchi Y (2008) Influence of pitavastatin on glucose tolerance in patients with type 2 diabetes mellitus. J Atheroscler Thromb 15:269-275

18. Gumprecht J, Gosho M, Budinski D, Hounslow N (2011) Comparative long-term efficacy and tolerability of pitavastatin $4 \mathrm{mg}$ and atorvastatin $20-40 \mathrm{mg}$ in patients with type 2 diabetes mellitus and combined (mixed) dyslipidaemia. Diabetes Obes Metab 13:1047-1055

19. Holman RR, Paul S, Farmer A, Tucker L, Stratton IM, Neil HA (2009) Atorvastatin in factorial with omega-3 EE90 risk reduction in diabetes (AFORRD): a randomised controlled trial. Diabetologia 52: $50-59$

20. Neil HA, Ceglarek U, Thiery J, Paul S, Farmer A, Holman RR (2010) Impact of atorvastatin and omega- 3 ethyl esters 90 on plasma plant sterol concentrations and cholesterol synthesis in type 2 diabetes: a randomised placebo controlled factorial trial. Atherosclerosis 213: $512-517$

21. Freed MI, Ratner R, Marcovina SM et al (2002) Effects of rosiglitazone alone and in combination with atorvastatin on the metabolic abnormalities in type 2 diabetes mellitus. Am J Cardiol 90:947-952

22. Konduracka E, Galicka-Latala D, Cieslik G et al (2008) Effect of atorvastatin on endothelial function and inflammation in longduration type 1 diabetic patients without coronary heart disease and arterial hypertension. Diabetes Obes Metab 10:719-725

23. Collins R, Armitage J, Parish S, Sleigh P, Peto R (2003) MRC/BHF heart protection study of cholesterol-lowering with simvastatin in 5963 people with diabetes: a randomised placebo-controlled trial. Lancet 361:2005-2016

24. Knopp RH, d'Emden M, Smilde JG, Pocock SJ (2006) Efficacy and safety of atorvastatin in the prevention of cardiovascular end points in subjects with type 2 diabetes: the atorvastatin study for prevention of coronary heart disease endpoints in non-insulin-dependent diabetes mellitus (ASPEN). Diabetes Care 29:1478-1485

25. Colhoun HM, Betteridge DJ, Durrington PN et al (2004) Primary prevention of cardiovascular disease with atorvastatin in type 2 diabetes in the Collaborative Atorvastatin Diabetes Study (CARDS): multicentre randomised placebo-controlled trial. Lancet 364:685-696

26. Tajima N, Kurata H, Nakaya N et al (2008) Pravastatin reduces the risk for cardiovascular disease in Japanese hypercholesterolemic patients with impaired fasting glucose or diabetes: diabetes subanalysis of the Management of Elevated Cholesterol in the 
Primary Prevention Group of Adult Japanese (MEGA) study. Atherosclerosis 199:455-462

27. Diabetes Atorvastin Lipid Intervention Study Group (2001) The effect of aggressive versus standard lipid lowering by atorvastatin on diabetic dyslipidemia: the DALI study: a double-blind, randomized, placebo-controlled trial in patients with type 2 diabetes and diabetic dyslipidemia. Diabetes Care 24:1335-1341

28. Jadad AR, Moore RA, Carroll D et al (1996) Assessing the quality of reports of randomized clinical trials: is blinding necessary? Control Clin Trials 17:1-12

29. DerSimonian R, Laird N (1986) Meta-analysis in clinical trials. Control Clin Trials 7:177-188

30. Nordin G, Dybkaer R (2007) Recommendation for term and measurement unit for 'HbA1c'. Clin Chem Lab Med 45:1081-1082

31. Higgins JP, Thompson SG (2002) Quantifying heterogeneity in a meta-analysis. Stat Med 21:1539-1558

32. Higgins JP, Thompson SG, Deeks JJ, Altman DG (2003) Measuring inconsistency in meta-analyses. BMJ 327:557-560

33. Egger M, Davey SG, Schneider M, Minder C (1997) Bias in metaanalysis detected by a simple, graphical test. BMJ 315:629-634

34. Cholesterol Treatment Trialists (2012) The effects of lowering LDL cholesterol with statin therapy in people at low risk of vascular disease: meta-analysis of individual data from 27 randomised trials. Lancet 380:581-590
35. Ray KK, Seshasai SR, Wijesuriya S et al (2009) Effect of intensive control of glucose on cardiovascular outcomes and death in patients with diabetes mellitus: a meta-analysis of randomised controlled trials. Lancet 373:1765-1772

36. Ridker PM, Danielson E, Fonseca FA et al (2008) Rosuvastatin to prevent vascular events in men and women with elevated C-reactive protein. N Engl J Med 359:2195-2207

37. Goldfine AB (2012) Statins: is it really time to reassess benefits and risks? N Engl J Med 366:1752-1755

38. Yada T, Nakata M, Shiraishi T, Kakei M (1999) Inhibition by simvastatin, but not pravastatin, of glucose-induced cytosolic $\mathrm{Ca} 2+$ signalling and insulin secretion due to blockade of L-type Ca2+ channels in rat islet beta-cells. Br J Pharmacol 126:1205-1213

39. Mabuchi H, Higashikata T, Kawashiri M et al (2005) Reduction of serum ubiquinol-10 and ubiquinone-10 levels by atorvastatin in hypercholesterolemic patients. J Atheroscler Thromb 12:111119

40. Nakata M, Nagasaka S, Kusaka I, Matsuoka H, Ishibashi S, Yada T (2006) Effects of statins on the adipocyte maturation and expression of glucose transporter 4 (SLC2A4): implications in glycaemic control. Diabetologia 49:1881-1892

41. Hao M, Head WS, Gunawardana SC, Hasty AH, Piston DW (2007) Direct effect of cholesterol on insulin secretion: a novel mechanism for pancreatic beta-cell dysfunction. Diabetes 56:2328-2338 